\title{
ESTAGIÁRIO: PERCEPÇÃO DE ALUNOS E PROFESSORES
}

\section{Vanusa Rosa Falqueto Fracarole ${ }^{1}$ \\ Larícia Olária Emerick Silva² \\ Danielle Marques Alvaristo ${ }^{3}$ \\ Glaucia Maria Ferrari ${ }^{4}$}

Resumo: Este trabalho tem por objetivo apresentar a concepção do professor regente e dos alunos do Ensino Fundamental em relação à presença e à participação do aluno-estagiário de Ciências Biológicas durante as aulas de ciências. Considerando que uma boa relação entre aluno-professor é de extrema importância durante o processo de ensino-aprendizagem, o aluno-estagiário deve refletir e exercitar durante sua formação essa afinidade na convivência com os alunos. A partir dos dados coletados foi possível perceber que o estágio supervisionado colaborou no processo da construção dos saberes do alunoestagiário, pois tanto os alunos quanto o professor regente reconhecem ser de extrema importância essa convivência na formação do futuro professor.

Palavras-chave: Estagiário; Estágio supervisionado; Formação Docente.

\footnotetext{
1 Graduanda do curso de Licenciatura em Ciências Biológicas do Instituto Federal do Espírito Santo (IFES) Campus de Alegre, ES, Brasil. E-mail: vanusafracarole@hotmail.com.

2 Graduanda do curso de Licenciatura em Ciências Biológicas do Instituto Federal do Espírito Santo (IFES) Campus de Alegre, ES, Brasil. E-mail: lariciaemericklara@hotmail.com.

3 Graduanda do curso de Licenciatura em Ciências Biológicas do Instituto Federal do Espírito Santo (IFES) Campus de Alegre, ES, Brasil. E-mail: dannimaarques@live.com.

${ }^{4}$ Prof. ${ }^{a}$. de Estágio Supervisionado I do Instituto Federal do Espírito Santo (IFES) - Campus de Alegre, ES, Brasil. E-mail: ferrari.glaucia@gmail.com.
} 